\title{
A Randomized Control Trial to Determine the Effect of Foot Reflexology on Intensity of Pain and Quality of Sleep in Post Caesarean Mothers
}

\author{
Jipi Varghese ${ }^{1}$ (corresponding author), Jobby George ${ }^{2}$, \\ Yathikumara Swamy Gowda ${ }^{3}$, \\ ${ }^{I} P h D$ Researcher in obstetrics and gynaecology nursing, Yenepoya University, University road, Derlakkate \\ 575018, Mangalore Karnataka India \\ ${ }^{2}$ PhD Researcher in Physiotherapy, specialization in psychiatry, Yenepoya University, Mangalore Karnataka \\ state, India. \\ ${ }^{3} \mathrm{PhD}$ Researcher in medical surgical nursing, Yenepoya University, University road, Derlakkate 575018, \\ Mangalore Karnataka India.
}

\begin{abstract}
:
Background: Caesarean section is one of the most commonly performed abdominal surgeries on the woman throughout the world with incidence of 20-25\% in many developed countries. ${ }^{4}$ In India caesarean section rates have skyrocketed especially in private sector where caesarean section rate was found to be $47 \%$ in contrast to $38 \%$ in charitable hospitals and 20\% in public hospitals according to a population -based cross sectional study in Chennai, India. In the early 1970s researchers reported that pain was seriously undertreated aspect after surgery. New medications and the recognition of complimentary pain management strategies have contributed to the improved ability to manage pain and to provide satisfactory pain reduction and/or relief. ${ }^{9}$ Reflexology is a sensational, dynamic yet simple approach to glowing health. Touch could induce pain relief by activating the large beta afferent nerve fibres from receptors in the skin as they connect with the cells in dorsal horn of the spinal cord. Stimulation of these fibres by stroking skin has been found to affect the activity of these nociceptive cells in the dorsal horn close the gate on the barrage of painful xi stimuli reaching the brain. The nurse is important health care personnel who can help the post operative mother who have undergone caesarean section in her pain management.

Results: Mean PSQI were found to be significantly lower in the intervention group $(p<0.001)$ than in the control group. The post test mean score of pain of an experimental group was significantly lower than of a control group $(X=4.75, X=7.65, t=-10.627, p<.001)$. Also, there was a significant difference between groups in terms of the pain intensity and requesting for analgesic $(p<.001)$. The research hypothesis was accepted which indicates that after receiving foot reflexology therapy, the subjects showed significant pain relief and improved quality of sleep.

Conclusion: The findings of the study support the need of implementing foot reflexology to post operative pain and improve the quality of sleep among post caesarean mothers. Foot reflexology is a non pharmacological, cost effective and simple intervention without any adverse effects. The results proved that the foot reflexology was effective in reducing the post operative pain among post caesarean mothers.
\end{abstract}

Keywords: Foot reflexology, pain, quality of sleep, Post Caesarean Mothers, Caesarean section, effectiveness.

\section{Introduction}

Child birth is one of the greatest events in every woman's life. Though it is the happiest moment, the process of child birth is physically painful. Caesarean section is one of the common methods of delivery with incidence of Thirty-two percent of all births in the United States. India is also experiencing a rapid increase in C-section deliveries with incidence of $32.6 \%$ documented from South India. Post operative pain and insomnia are the major concerns for the mother. Some alternative therapies are in the early empirical stage in reducing post operative pain and improving quality of sleep. ${ }^{1}$

A study to find the Effect of foot and hand massage in post cesarean pain control in a group of Turkish mothers revealed that the reduction in pain intensity was significantly meaningful in both intervention, when compared to the control group ${ }^{5}$.

A study done in New Delhi, India to know the effectiveness of foot reflexology on pain among postoperative patients showed that there was a 50\% reduced use of analgesics in the experimental group where foot reflexology was used for pain control, against the control group were only analgesics were administered. The study concluded that foot reflexology was effective in reducing post operative pain ${ }^{6}$. 


\subsection{Need Of The Study}

Post operative pain and quality of sleep are routinely controlled by pharmacological measure alone. Complementary strategies based on sound research findings are needed to aid in post operative pain relief and improve quality of sleep ${ }^{2}$. Article published by kneaded bodyworks wellness center explained that, regular foot reflexology for post-cesarean mothers can relieve the stress of delivery by facilitating recovery of the postpartum woman and providing emotional support for the transition into motherhood who are recuperating from major abdominal surgery, as well as the strain of pregnancy. Massaging the feet and hands stimulates the mechanoreceptors that activate the "non-painful" nerve fibers, preventing pain transmission from reaching consciousness and induce sleep. ${ }^{3}$

\subsection{Clinical Significance}

Touch has always been a part of the nursing mandate and reflexology has become a part of this reach out to patients. The use of reflexology by nurses is easy and practical as noted by one nurse researcher who writes: It can be performed at any location, is non-invasive, and does not interfere with patients' privacy. ${ }^{4}$

\subsection{History}

Reflexology was introduced to the United States in 1913 by William H. Fitzgerald, M.D an ENT specialist, and Dr. Edwin Bowers. ${ }^{9}$ Fitzgerald claimed that applying pressure had an anesthetic effect on other areas of the body.

- Alternative medicine with powerful healing practice

- Physical act of applying pressure to the feet, hands, or ears - With specific thumb, finger, and hand techniques without the use of oil or lotion

- Zones and reflex points in the feet correspond with specific glands and organs within the body can have therapeutic effects. ${ }^{8}$

Reflexology was modified in the 1930s and 1940s by Eunice D. Ingham (1889-1974), a nurse and physiotherapist. Ingham claimed that the feet and hands were especially sensitive, and mapped the entire body into "reflexes" on the feet renaming "zone therapy" to reflexology. Ingham's theories are prominent in the United States and United Kingdom, although modern methods also exist. ${ }^{10,11}$

Practices resembling reflexology may have existed in previous historical periods. Although its origins are not well documented, there are reliefs on the walls of a Sixth Dynasty Egyptian tomb ,In ancient Egypt around 2500-2300BC Ankhm'ahor was laid to rest. His tomb is known as 'the physicians tomb' as many medical scenes are depicted including a pictograph detailing two men working on the feet and hands of another two men, that depict two seated men receiving reflexology on their hands and feet ${ }^{12}$.

\section{It dates back to ancient times -}

Chinese have discovered that nerves in the feet are connected to various internal organs, and hence problems in these organs can be cured by applying pressure on the nerve endings .Individual meridians either begin or end in the hands or feet, perhaps this is one of the reasons reflexology 5000 years ago was viewed to be effective and presently still is. ${ }^{13}$

British:-In the 1890's in London Sir Henry Head conducted neurological studies proving the neurological relationship that exists between skin and internal organs. In 1932 Sir Charles Sherrington won the Nobel Prize when he proved that the whole nervous system adjusts to a stimulus, thus contributing to the development of zone theory. ${ }^{13}$

\subsection{OBJECTIVES}

1. To assess the effectiveness of foot reflexology on intensity of pain in mothers following caesarean section.

2. To assess the effectiveness of foot reflexology on quality of sleep in mothers following caesarean section

\subsection{Hypothesis}

H1: There will be significant difference between the pre-test level and post test level of post caesarean pain in both experimental and control group.

H2: There will be significant difference between the pre-test level and post test level of quality of sleep in both experimental and control group. 
Fig 1 Conceptual Framework of Foot Reflexology on Post Caesarean Mothers based on Roy's Adaptation Model

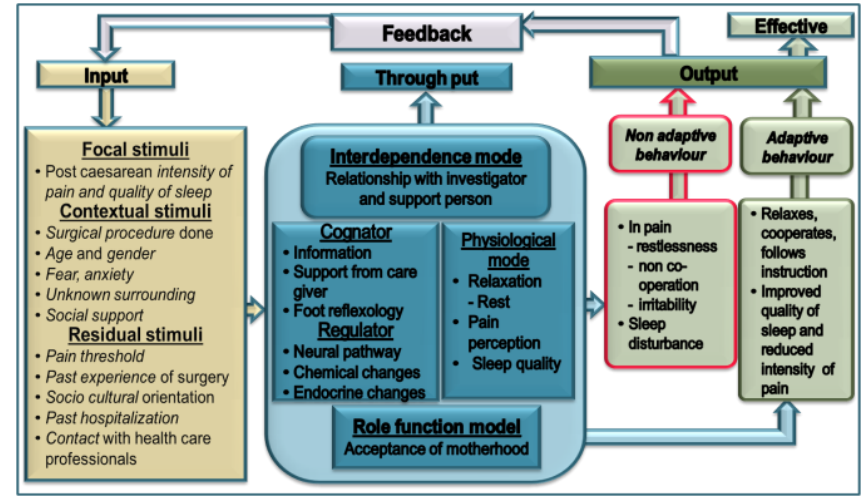

Fig 2 Schematic Representation of the Research Design

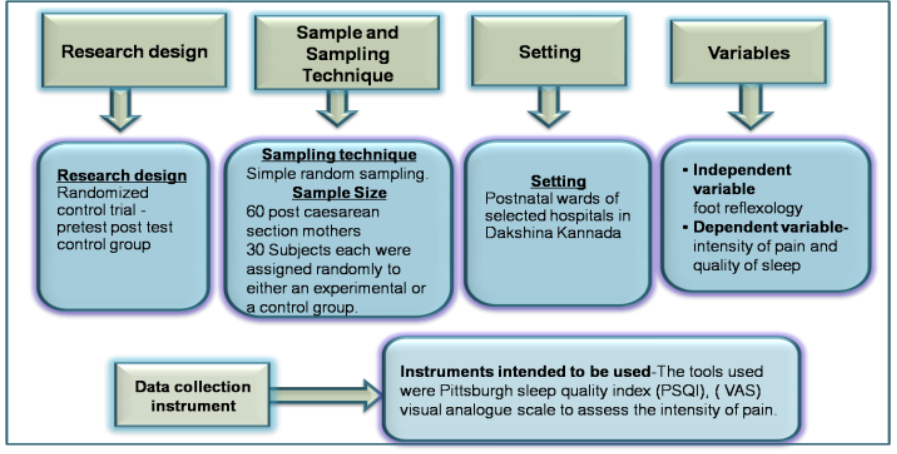

\section{Methodology}

2.1 Source of data -Mothers undergone caesarean section

2.2 Population - Post caesarean mothers.

2.3 Sampling procedure - Simple random sampling.

2.4 Sample size -60 post caesarean section mothers .30 Subjects each were assigned randomly to either an experimental or a control group.

2.5 Research design - Randomized control trial- pretest post test control group design.

Table 1 Research design

\begin{tabular}{|l|l|l|l|}
\hline Study subjects & Pre test & Intervention & Post test \\
\hline $\begin{array}{l}\text { Experimental } \\
\text { group }\end{array}$ & 01 & $\mathrm{X}$ & 02 \\
\hline Control group & 01 & - & 02 \\
\hline
\end{tabular}

\section{In this study:-}

\section{1- Pre test, X- Intervention (foot reflexology) ,02- Post test, - No intervention}

\subsection{0sampling Criteria} Inclusion criteria

- Who are willing to participate in the study.

- Post caesarean section mothers from 1st -3rd post operative day (Mothers who are out of the effect of anaesthesia).

- Who were able to comprehend English/Kannada.

\section{Exclusion criteria}

- With severe post-operative maternal or fetal complications.

- Postpartum Hemorrhage

- Diagnosed with post partum psychiatric disorders

- Using any other complementary therapies.

- Having painful (trauma, blisters, warts, open sore wound fracture) or infectious feet, HIV, HEP B AND C. 
1.7 Instruments intended to be used- The tools used were Pittsburgh sleep quality index (PSQI), (VAS) visual analogue scale to assess the intensity of pain.

\subsection{Preparation before reflexology.}

a) For mother: - Clean and warm the feet soak the feet in warm water for 10 minutes with the temperature the mother can tolerate and dry the feet. Lie down or sit in a comfortable position

b) For therapist:-Explain the procedure and make her to relax cut short the nails. Hands should be free of trauma.

c) Techniques used in the study:-Thumb walking and finger walking.

d) Areas of the foot stimulated-Brain, eye, adrenal, respiratory organ, spine, circulating systems, and lower abdomen.

\subsection{Data Collection And Analysis}

a) Randomized control trial with

ethical clearance obtained from hospital research committee

Followed by informed consent of 60 post caesarean section mothers from 1 st-3rd post operative day. 30 Subjects each were assigned randomly to either an expérimental or a control group. Baseline data was obtained from both the groups.

Participants in both groups received the same care except for reflexology.

Intervention group received a single 15-minute foot reflexology session at the same time each evening for five consecutive days. After 5 days of treatment, intensity of pain was measured by visual analogue scale (VAS) and quality of sleep was assessed by Pittsburgh sleep quality index (PSQI).The data was analyzed using descriptive and inferential statistics.

\section{Results}

1.1 The distribution of sample according to their demographic data:

Most of the subjects in the experimental age group were in the age group $10(36.70 \%)$ were in the age group 26-29 years, whereas most of the subjects in the control group $(36.70 \%)$ belong to the age group $\geq 30$ years. Majority of the subjects in the experimental group were Hindus $(90 \%)$, in the control group majority of the subjects were Hindus (93.30\%).With regards to the caesarean section in the past $(69.20 \%)$ had one or more previous deliveries with caesarean section in the experimental group. In the control group (69.20\%) had one or more previous deliveries with caesarean section and (30.80\%) did not have caesarean section in the past.

\subsection{Before the intervention:}

$\checkmark$ no statistically significant difference in pain intensity between two groups by using t-test and

$\checkmark \quad$ Mean PSQI scores and pain intensity for both groups declined over time between pre test and post test.

1.3 After the intervention:

$\checkmark \quad$ Mean PSQI were found to be significantly lower in the intervention group $(\mathrm{p}<0.001)$ than in the control group.

$\checkmark$ The post test mean score of pain of an experimental group was significantly lower than of a control group $(X=4.75, X=7.65, \mathrm{t}=-10.627, \mathrm{p}<.001)$.

$\checkmark$ Also, there was a significant difference between groups in terms of the pain intensity and requesting for analgesic $(\mathrm{p}<.001)$.

The research hypothesis was accepted which indicates that after receiving foot reflexology therapy, the subjects showed significant pain relief and improved quality of sleep.

Fig 3 Mean pain intensity score in pre test and post test control and experimental group

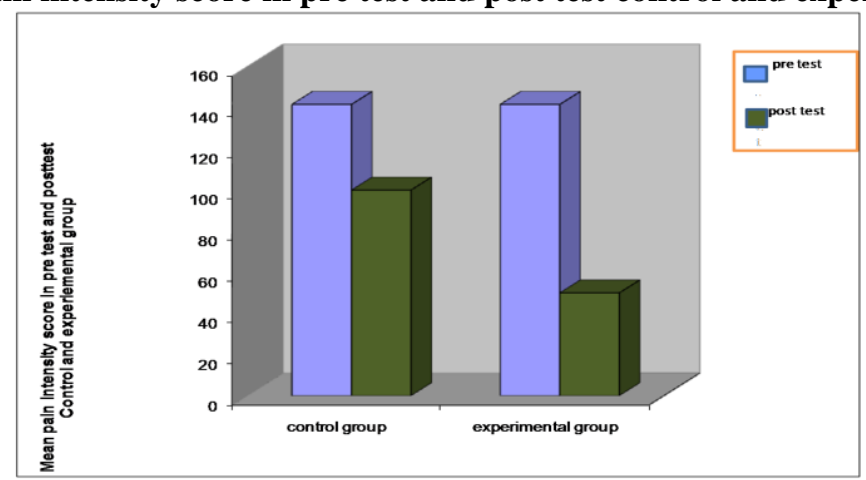


Fig 4 Mean pain intensity score in pre test and post test control and experimental group

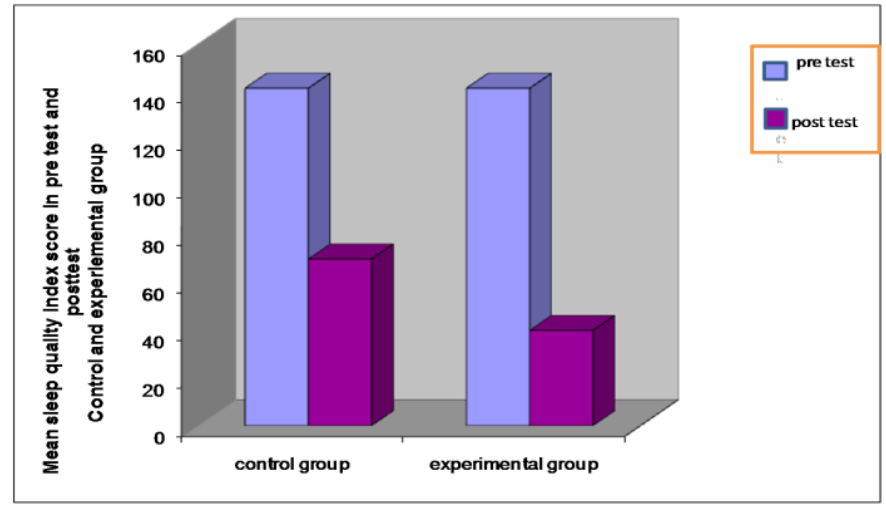

\section{Recommendations}

The study can be replicated on a larger sample to generalise the results

The comparative study can be conducted with more than one intervention

Non pharmacological pain management should be emphasised in nursing curriculum

- Training programmes Nurses can be given on complementary therapies

- Complementary therapy cell -could be arranged at an institution and multidisciplinary team could be introduced

\section{Limitations}

a) Intervention was limited to 15 minutes.

b) Study was conducted only on post caesarean mothers.

c) Relatively small sample size.

d) Study results are limited to Indian population.

\section{Conclusion And Summary}

a) Foot reflexology following caesarean section significantly improved the quality of sleep and reduced the intensity of pain.

b) Nurses interested in alternative therapies should be encouraged to obtain training in alternative therapy especially reflexology and to apply it in clinical settings if it is allowed.

c) As this study has opened up a new zone for independent nursing practice, its potentiality requires further exploration.

\section{Reference}

[1] Klaus M H, Kennel JH,Human maternal behaviour at the first contact with her youngone. Paediatrics ,www.answer.com

[2] Chacko L. Impact of foot massage on the level of pain, Heart rate and BP among patients with abdominal surgery in selected hospital at Mangalore(unpublished masters in nursing dissertation,RGUHS,Bangalore,2008).

[3] MSassage specialities and modalities, kneaded bodyworks wellness center, http://www.kneadedbodyworks.com/id1.html

[4] http://www.reflexology-research.com/nursereflexology.html

[5] Nuriye Degirmen, Nebahat Ozerdogan, Deniz Sayiner. Effectiveness of foot and hand massage in postcesarean pain control in a group of Turkish pregnant women.Applied Nursing Research volume 23, Issue 3, Pages 153-158..August 2010 http://www.appliednursingresearch.org/article/S0897-1897(08)00081-5/abstract

[6] Chaudhary S,Kumar G,Singh K.Reflexology research of post operative pain reduction.Reflexions 2006 Mar:27(1).

[7] Kunz, Kevin; Kunz, Barbara (1993). The Complete Guide to Foot Reflexology. Reflexology Research Project.

[8] Norman, Laura; Thomas Cowan (1989). The Reflexology Handbook, A Complete Guide. Piatkus. pp. 17. ISBN 0-86188-912-6.

[9] Benjamin, Patricia (1989). "Eunice D. Ingham and the development of foot reflexology in the U.S". American Massage Therapy Journal.

[10] Massagenerd.com Presents History of Massage, Therapies \& (pdf).http://www.massagenerd.com/pdf_massage_ebooks/History_Therapies_Rules_Ryan_Hoyme_.pdf. Retrieved 2007-10-12.

http://www.intelihealth.com/IH/ihtIH/WSIHW000/8513/34968/360060.html?d=dmtContent. Retrieved January 27, 2007.

[12] http://www. reflexologyfeetfirst.co.uk/history.html

[13] Roy CS .Introduction to nursing .An adaptation model USA .Prentice Hall Publication 1984 